\title{
Risk Analysis of Eculizumab-Related Meningococcal Disease in Japan Using the Japanese Adverse Drug Event Report Database
}

This article was published in the following Dove Press journal:

Drug, Healthcare and Patient Safety

\section{Yumi Matsumura}

Department of Patient Safety, Kyoto University Hospital, Sakyo-ku, Kyoto, Japan
Correspondence: Yumi Matsumura Department of Patient Safety, Kyoto University Hospital, 54 Kawaharacho, Shogoin, Sakyo-ku, Kyoto 606-8507, Japan Tel +8I 7575 I 4694

Fax +8I 75 75I 4563

Email yumatsu@kuhp.kyoto-u.ac.jp
Purpose: Eculizumab, a drug that blocks activation of the terminal complement pathway, is useful in the treatment of several rare diseases. However, eculizumab-related meningococcal disease is a serious problem. Because of the difficulty diagnosing meningococcal disease, deaths from meningococcal disease may have been overlooked. The purpose of this study was to clarify the trend of meningococcal infection in patients on eculizumab and to evaluate the effectiveness of risk communication.

Methods: Pharmacovigilance analysis was conducted using the Japanese Adverse Drug Event Report database between the first quarter of 2010 and the second quarter of 2019. Of the reports of deaths, those with adverse event terms of fever, shock, altered state of consciousness, loss of consciousness, sepsis, organ failure, and disseminated intravascular coagulation were analyzed as deaths with suspected meningococcal infection.

Results: Of the 3559.2 person-years of eculizumab-exposed patients, 17 patients died with symptoms of meningococcal disease (including two confirmed cases). The mortality rate of meningococcal disease in patients exposed to eculizumab in Japan was estimated to be 0.56 (confirmed cases) to 4.8 (suspected cases) per 1000 person-years. Based on data from the National Epidemiological Surveillance of Infectious Disease, the mortality rate of meningococcal disease in the general population in Japan is 0.0042 per 100,000 person-years. Thus, the mortality rate from meningococcal disease in eculizumab-exposed patients is estimated to be 13,000 to 114,000 times the mortality rate from meningococcal disease in the general population of Japan. Academic societies warned of deaths from meningococcal disease in the first quarter of 2018, calling for appropriate action. Thereafter, only one death with symptoms of meningococcal disease has been reported.

Conclusion: The analysis of the database showed that death from meningococcal disease in eculizumab-exposed individuals may occur more often than expected. This study also showed that appropriate risk communication reduced the fatality rate of meningococcal disease.

Keywords: Neisseria meningitidis, post-marketing surveillance, incidence, mortality rate, case-fatality rate, risk communication

\section{Introduction}

Eculizumab is a drug that inhibits the terminal complement activation pathway after complement C5. There are currently four indications for eculizumab: paroxysmal nocturnal hemoglobinuria (PNH), atypical hemolytic uremic syndrome (aHUS), generalized myasthenia gravis (gMG), and neuromyelitis optica spectrum disorders (NMOSDs). These are chronic diseases that significantly reduce patients' quality of 
life (QOL). The advent of eculizumab enabled the inhibition and suppression of the activation of complement, which is involved in the development of these diseases, and significantly improved the QOL of these patients. On the other hand, complement activation also prevents formation of the membrane attack complex that is essential for meningococcal serum bactericidal activity, ${ }^{1}$ and, therefore, eculizumab increases the risk of meningococcal disease. As of 2019, the incidence of meningococcal disease in eculizumab-exposed patients was 3.0 per 1000 personyears (149 per 49,047 person-years), and the mortality rate of meningococcal disease was 0.34 per 1000 person-years (10 per 29,792 person-years) as of $2017 . .^{2,3}$

Neisseria meningitidis, the causative bacterium, invades sterile blood and/or cerebrospinal fluid, causing invasive meningococcal disease, in which the main symptoms are sepsis and/or meningitis. The initial symptoms are similar to those of common viral diseases, such as fever, headache, vomiting, and upper respiratory tract symptoms, and they last 4 to $8 \mathrm{~h}$. Around 9 to $12 \mathrm{~h}$ after onset, leg pain, cold hands and feet, and abnormal skin color (pallor or mottling) appear. The median time to onset of the classic meningococcal features of hemorrhagic rash, meningism, and impaired consciousness is 13 to 22 h. Patients are close to death by $24 \mathrm{~h}$ after the onset. It has been pointed out that early diagnosis and treatment are difficult because only nonspecific symptoms appear in the early stage. ${ }^{4}$ Even when the disease is diagnosed early and adequate treatment is started, $8 \%$ to $15 \%$ of patients die, often within 24 to $48 \mathrm{~h}$ after the onset of symptoms. Meningococcemia has a case-fatality rate of up to $40 \%{ }^{5}$

The incidence of meningococcal disease varies between 0.11 and 2.8 per 100,000 person-years in Europe, Australia, New Zealand, South America, and North America, ${ }^{5-11}$ and 112 per 100,000 person-years in the African meningococcal belt zone. ${ }^{12}$ In these countries, vaccination has been publicly implemented, and the incidence has decreased. However, in Japan, the incidence is low, at 0.028 per 100,000 person-years, without vaccination. ${ }^{13}$ The serogroup distribution varies by region of the world. In Europe, the United States, and Australia, $\mathrm{B}, \mathrm{C}$, and $\mathrm{Y}$ serogroups account for the majority of the serogroups, whereas serogroup $\mathrm{Y}$ is the most dominant serogroup, followed by B, C, and W in Japan. ${ }^{14}$ Carriage rates in Europe and the United States have been estimated to range from $10 \%$ to $35 \%$ in young adults. ${ }^{15}$ In Japan, only $0.4 \%$ of the population have Neisseria meningitidis in their throat. ${ }^{16}$ The low incidence in Japan may be attributable to the low meningococcal carriage rate.

In Japan, most physicians have never seen meningococcal disease cases in their lifetime. Eculizumab has appeared in that situation, and clinicians in the primary and ambulatory settings can suddenly find themselves seeing patients with meningococcal disease. They are neither specialists in diseases for which eculizumab is indicated nor experts in meningococcal disease. By August 2019, 6 confirmed cases of meningococcal disease, including two deaths, had been reported in patients exposed to eculizumab in Japan, as shown later. However, meningococcal disease may have been missed in some of the deaths in eculizumab-treated patients.

In Japan, active post-marketing surveillance based on a risk management plan is conducted for a certain period for all patients using eculizumab, and post-marketing adverse drug reactions (ADRs) are systematically collected. All-case post-marketing surveillance is a Japanesespecific survey method that is not usually used in other countries and has no selection bias. ${ }^{17}$ ADR information is registered and released in the Japanese Adverse Drug Event Report (JADER) database provided by the Pharmaceuticals and Medical Devices Agency (PMDA). Using this database, the possibility that meningococcal infection in patients using eculizumab in Japan was overlooked was investigated, and the effectiveness of a risk minimization plan was evaluated.

\section{Materials and Methods Information on Eculizumab-Related Meningococcal Disease from the JADER Database}

In this study, data were obtained from the public release of PMDA's JADER database, which is freely available and contains information on ADRs and patients in Japan. The database contains information on suspected ADRs, including reporting year/quarter, reporter occupation, reporting category, sex, age, height, weight, outcome, underlying disease, single dose, administration start date, administration end date, administration route, application reason, discontinuation/reducing dose/unchanged dose of suspected drug, presence or absence of recurrence due to readministration, evaluation, side effects/adverse events, onset date, name of suspected drug, name of other drugs used, and so on. The reporting category is either a test (mandatory) report or a voluntary report. All cases are 
classified as "test" when a systematic survey is performed and reported, and "voluntary" when a healthcare professional reports a spontaneous observation.

To extract cases suspected of meningococcal disease, the following terms of ADRs such as fever, hyperthermia, shock, altered state of consciousness, loss of consciousness, sepsis, organ failure, and disseminated intravascular coagulation (DIC) were used based on Thompson's report. ${ }^{4}$ Cases in which certain diagnoses other than meningococcal disease, such as enterococcal sepsis, Klebsiella bacteremia, streptococcal sepsis, and so on, were made were excluded from suspected meningococcal disease.

There is a limit to the accuracy and reliability of the information; there are missing values, and the database contains duplicate data.

\section{Risk Information from PMDA, The Company, and Academic Associations}

Review reports and risk management plans at the time of approval were obtained from the PMDA website, and risk communication materials for healthcare professionals or patients were obtained from the company website. Information on alerts regarding meningococcal disease in eculizumab-exposed patients was collected from the website of each academic association.

\section{Information on Meningococcal Disease in the General Population in Japan}

The number of patients with meningococcal disease in the general population in Japan was obtained from the publication based on the National Epidemiological Surveillance of Infectious Disease (NESID). ${ }^{14}$ The population data were obtained from the portal site of official statistics of Japan, e-Stat. ${ }^{18}$ Both datasets are provided by the government and freely available.

\section{Results}

\section{Trend in Incidence and Frequency of Adverse Drug Reactions and Deaths}

As shown in Figure 1, a total of 462 ADR reports were obtained between the first quarter of 2010 and the second quarter of 2019. Of these, 6 cases in which fetuses were exposed in their mother's uterus were excluded, and 456 reports were analyzed for this study. There were 67 deaths. Of the 456 cases, the primary diseases were PNH in 326

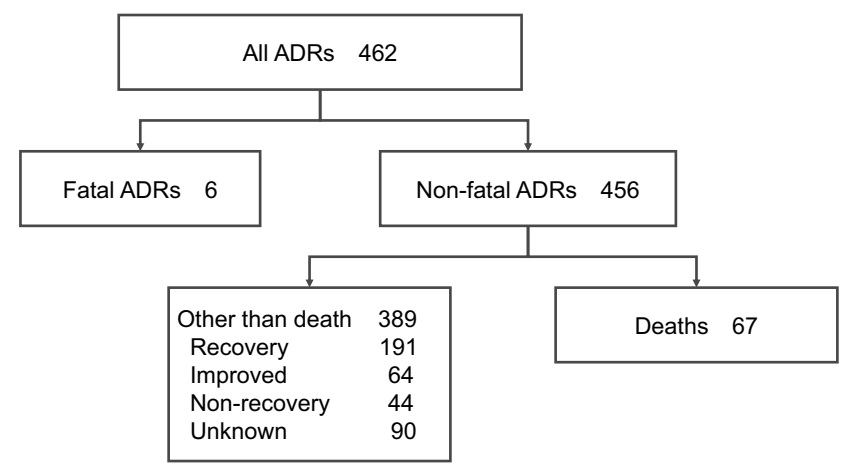

Figure I Flowchart of this study.Note: Data from Pharmaceuticals and Medical Devices Agency. ADR information for eculizumab from the first quarter of 2010 to the second quarter of 2019. Available from: (https://www.pmda.go.jp/safety/infoservices/drugs/adr-info/suspected-adr/0003.html). ${ }^{19}$ See materials and methods section for detail.

cases, aHUS in 105 cases, and gMG in 21 cases. There were 3 off-label uses and 1 blank.

The number of reports of suspected ADRs and suspected deaths due to eculizumab in each fiscal year/quarter is shown in Figure 2. The number of reports of ADRs is increasing. The number of deaths has been several in each quarter since around 2015, showing an increasing trend until around the third quarter of 2018. The number of deaths decreased after the fourth quarter of 2018.

Suspected cases of deaths from meningococcal disease were then extracted. Of the 67 fatal cases, 18 cases, $27 \%$ of all deaths, showed either or several of fever, hyperthermia, shock, altered state of consciousness, loss of consciousness, sepsis, organ failure, and DIC, or a confirmed diagnosis of meningococcal disease. The number of reports in each fiscal year/quarter of the 18 suspected deaths from meningococcal disease is shown in Figure 3. One voluntary report in the first quarter of 2018 and one in the second quarter of 2018 showed the same dates of onset of ADRs, sex, height, and weight and were regarded as duplicate reports.

\section{Suspected Mortality Rate and Case-Fatality Rate of Eculizumab-Related Meningococcal Disease in Japan}

Seventeen fatal cases of suspected meningococcal disease are summarized in Table 1. The age distribution of the fatalities can be divided into two groups: those under 40 and those over 60 years. Given at least 2 and at most 17 deaths per 3559.2 person-years of eculizumab-exposed patients during the period, ${ }^{2}$ the mortality rate of eculizumab-related meningococcal disease in Japan was estimated to be at least 0.56 to at most 4.8 per 1000 person-years. 


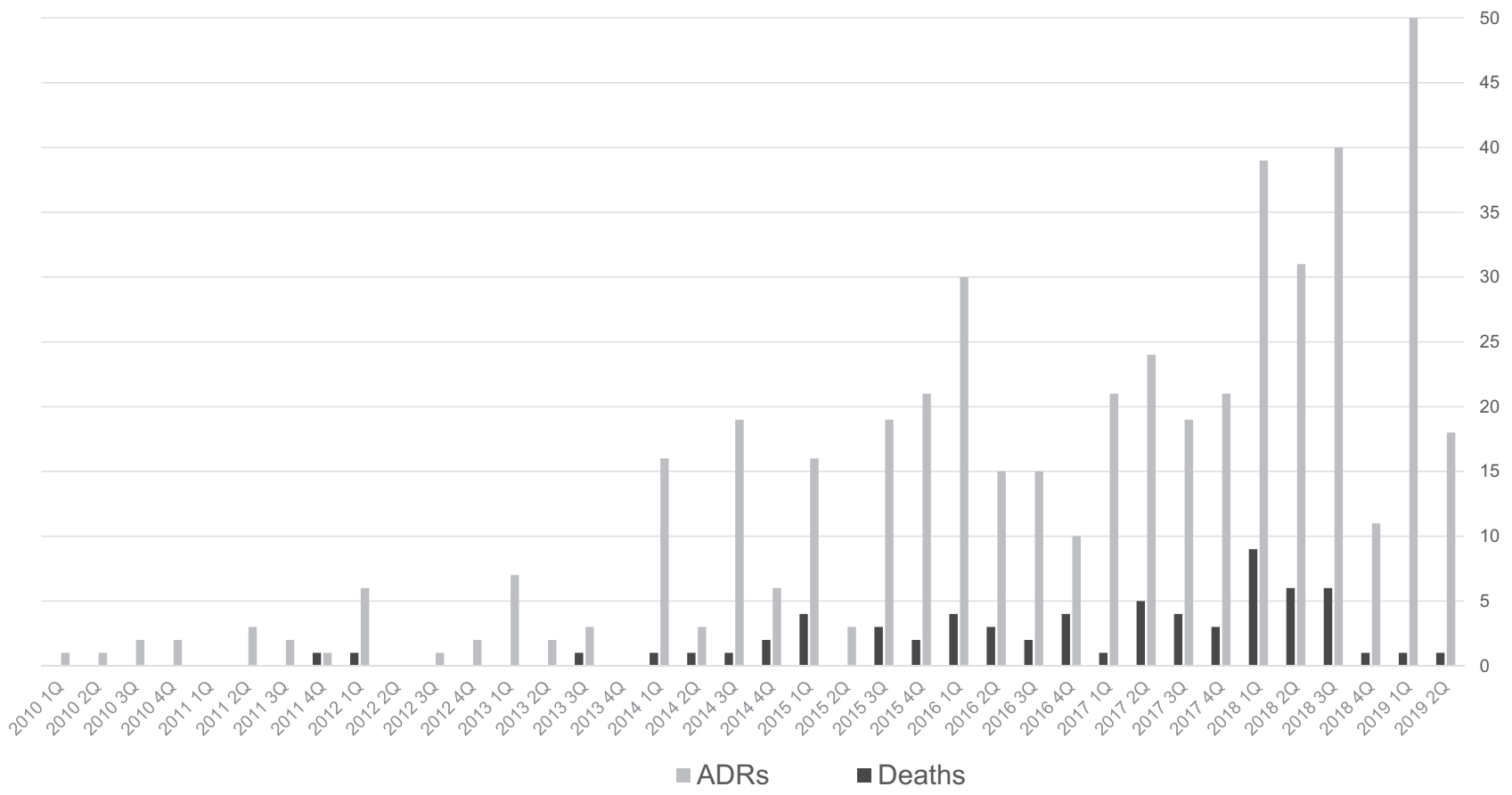

Figure 2 Number of reports of ADRs and deaths in patients exposed to eculizumab for each reporting year/quarter between 2010 and 2019.

Note: The number of ADRs includes the number of deaths. The reporting year is the fiscal year (the fiscal year is from April to March of the following year). For the second quarter of 2019, data are for the two months of July and August 2019.

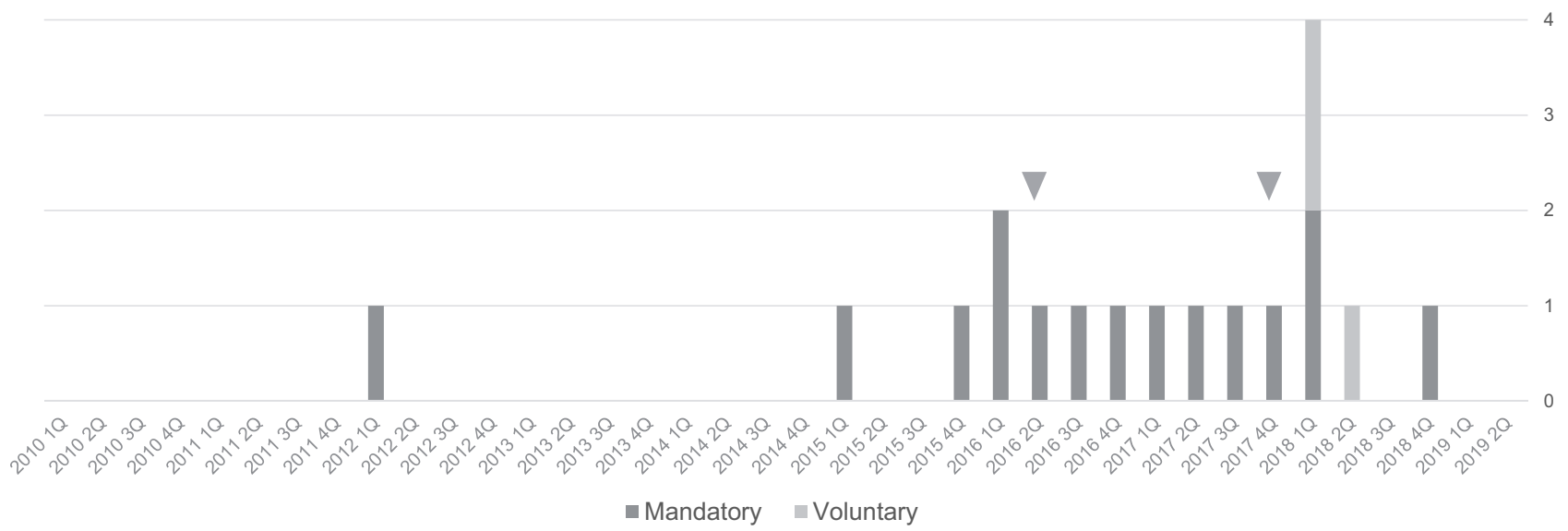

Figure 3 Number of reports of deaths with symptoms of suspected meningococcal disease in patients exposed to eculizumab for each reporting year/quarter between 2010 and 2019.

Note: Two cases $(\boldsymbol{\nabla})$ in the second quarter of 2016 and in the fourth quarter of 2017 are definite meningococcal disease. There are 3 voluntary reports between the first quarter and the second quarter of 2018 .

Six patients with a definite diagnosis of meningococcal disease are listed in Table 2. The first meningococcal case was a fatal case. If meningococcal disease included only the 6 cases, the incidence of meningococcal disease in individuals receiving eculizumab was 1.7 per 1000 person- years, and the case-fatality rate of eculizumab-related meningococcal disease in Japan was $33 \%$ as of 2019.

The number of people with definite meningococcal disease in the general population was 160 (including 24 deaths) between April 2013 and October 2017, 
Table I Fatal Cases with Suspected Meningococcal Disease Symptoms

\begin{tabular}{|c|c|c|c|c|}
\hline & Age & $\begin{array}{l}\text { Reporting } \\
\text { Yearl } \\
\text { Quarter }\end{array}$ & $\begin{array}{l}\text { Primary } \\
\text { Disease }\end{array}$ & ADRs \\
\hline I & $20 \mathrm{~s}$ & $2016 / 2 Q$ & PNH & meningococcal sepsis \\
\hline 2 & $20 \mathrm{~s}$ & $2017 / 4 Q$ & $\mathrm{PNH}$ & meningococcal sepsis \\
\hline 3 & $30 \mathrm{~s}$ & $2016 / 4 Q$ & aHUS & $\begin{array}{l}\text { altered state of } \\
\text { consciousness }\end{array}$ \\
\hline 4 & $30 \mathrm{~s}$ & $2017 / 2 Q$ & aHUS & sepsis \\
\hline 5 & $40 \mathrm{~s}$ & $2017 / 1 Q$ & aHUS & $\begin{array}{l}\text { multiple organ dysfunction } \\
\text { syndrome }\end{array}$ \\
\hline 6 & $40 \mathrm{~s}$ & $2018 / 1 \mathrm{Q}$ & aHUS & $\begin{array}{l}\text { hyperthermia, altered state } \\
\text { of consciousness, hepatic } \\
\text { disorder }\end{array}$ \\
\hline 7 & $60 \mathrm{~s}$ & $2018 / 1 Q$ & aHUS & $\begin{array}{l}\text { septic shock, multiple } \\
\text { organ dysfunction } \\
\text { syndrome }\end{array}$ \\
\hline 8 & $70 \mathrm{~s}$ & $2012 / 1 Q$ & PNH & $\begin{array}{l}\text { septic shock, renal } \\
\text { insufficiency }\end{array}$ \\
\hline 9 & $70 \mathrm{~s}$ & $2015 / 4 Q$ & PNH & septic shock \\
\hline 10 & $70 \mathrm{~s}$ & $2017 / 3 Q$ & PNH & sepsis \\
\hline II & $70 \mathrm{~s}$ & $2018 / 1 Q$ & PNH & fever \\
\hline 12 & $80 \mathrm{~s}$ & $2015 / 1 Q$ & $\mathrm{PNH}$ & loss of consciousness \\
\hline 13 & $80 \mathrm{~s}$ & $2016 / 1 Q$ & aHUS & $\begin{array}{l}\text { DIC, multiple organ } \\
\text { dysfunction syndrome }\end{array}$ \\
\hline 14 & $80 \mathrm{~s}$ & $2018 / 1 Q$ & $\mathrm{PNH}$ & sepsis \\
\hline 15 & $80 \mathrm{~s}$ & $2018 / 4 Q$ & PNH & $\begin{array}{l}\text { altered state of } \\
\text { consciousness, DIC, } \\
\text { hepatic disorder }\end{array}$ \\
\hline 16 & $90 \mathrm{~s}$ & $2016 / 1 Q$ & PNH & DIC \\
\hline 17 & - & $2016 / 3 Q$ & PNH & septic shock \\
\hline
\end{tabular}

Note: - indicates missing value.

Abbreviations: ADRs, adverse drug reactions; $\mathrm{PNH}$, paroxysmal nocturnal hemoglobinuria; aHUS, atypical hemolytic uremic syndrome; DIC, disseminated intravascular coagulation.

according to NESID. The general population during the period was 572,032,000 person-years according to the demographics of the general population in Japan. The incidence of meningococcal disease in Japan can be calculated as 0.028 per 100,000 person-years, and the mortality rate can be calculated as 0.0042 per 100,000 person-years. The case-fatality rate in the general population was $15 \%$.

Based on the above results, meningococcal disease risk in patients on eculizumab is 6100 times the baseline risk of meningococcal disease in the general population, and the mortality rate of meningococcal disease in patients on eculizumab was estimated to be 13,000-114,000 times the mortality rate of meningococcal disease in the general population in Japan. The case-fatality rate of
Table 2 Cases with a Definite Diagnosis of Meningococcal Disease

\begin{tabular}{|l|l|l|l|l|l|}
\hline $\begin{array}{l}\text { Reporting } \\
\text { Yearl } \\
\text { Quarter }\end{array}$ & Age & $\begin{array}{l}\text { Primary } \\
\text { Disease }\end{array}$ & $\begin{array}{l}\text { Date of } \\
\text { Onset }\end{array}$ & Outcome \\
\hline I & $2016 / 2 \mathrm{Q}$ & 20 s & PNH & $2016 / 08 / 22$ & Death \\
2 & $2016 / 4 \mathrm{Q}$ & Under 10 & aHUS & $2016 / 12 / 02$ & Recovery \\
3 & $2017 / 4 \mathrm{Q}$ & $20 \mathrm{~s}$ & $\mathrm{PNH}$ & $2017 / 12 / 20$ & Recovery \\
4 & $2017 / 4 \mathrm{Q}$ & $20 \mathrm{~s}$ & $\mathrm{PNH}$ & $2018 / 01 / 28$ & Death \\
5 & $2018 / 4 \mathrm{Q}$ & $30 \mathrm{~s}$ & gMG & $2018 / 12 / 28$ & Unknown \\
6 & $2019 / 1 \mathrm{Q}$ & 10s & aHUS & $2019 / 4 / 18$ & Recovery \\
\hline
\end{tabular}

Abbreviations: $\mathrm{PNH}$, paroxysmal nocturnal hemoglobinuria; aHUS, atypical hemolytic uremic syndrome; gMG, generalized myasthenia gravis.

meningococcal disease in the eculizumab-exposed population was two times that in the general population.

\section{Effect of Risk Communication on the Frequency of Deaths from Suspected Meningococcal Disease}

Risk information from the marketing authorization holder, the regulatory authority, and the public (clinicians and patients) is summarized in Table $3 .^{20-27}$ In the second fatal case in Japan, a patient safety card was not presented to a physician in the emergency department. The clinical data showed a white blood cell count of $8900 / \mu \mathrm{L}$ and a CRP level of $0.07 \mathrm{mg} / \mathrm{dL}$. The flu was prevalent among the patient's colleagues, and he was treated with an anti-influenza drug. ${ }^{23}$

After the second fatal case, the marketing authorization holder released the safety information $2^{\text {nd }}$ report. The report included the fatal case, in which a patient safety card was not presented to a physician, and the recovered case, in which the card was presented and antibiotic treatment was started immediately. ${ }^{23}$ Shortly thereafter, in March through May 2018, the Japanese Society of Hematology, Japanese Society of Nephrology, Japanese Society of Neurology, and Japanese Pediatric Society released risk information regarding meningococcal disease and emphasized the importance of patient education. ${ }^{24-27}$

Since the above safety information was made available, the frequency of reports of deaths related to suspected meningococcal disease has been decreasing. There has been only one case of death from suspected meningococcal disease since the second quarter of 2018 (Table 1, Case 15 with DIC). Of note, soon after the release of the $2^{\text {nd }}$ safety information in the first quarter of 2018, 3 voluntary reports of death were provided by healthcare professionals. 
Table 3 Risk Information on Eculizumab-Related Meningococcal Disease

\begin{tabular}{|c|c|}
\hline Year/Month & Activities of Events \\
\hline 2016 Oct & $\begin{array}{l}\text { The marketing authorization holder released safety information and publicized the first death of meningococcal disease in Japan in } \\
\text { a patient receiving eculizumab. }{ }^{20}\end{array}$ \\
\hline $2017 \mathrm{Sep}$ & $\begin{array}{l}\text { The marketing authorization holder revised the package insert and added the information that there have been cases of } \\
\text { meningococcal disease including fatal cases even among patients immunized with meningococcal vaccine. }{ }^{21} \\
\text { The company also revised the patient safety card and stated that meningococcal disease may not be prevented even when } \\
\text { vaccinated, and meningococcal disease may quickly become severe and lead to death, and warned patients to receive immediate } \\
\text { treatment when they experience any of the symptoms of meningococcal disease. In the revised card, limb pain was added as one of } \\
\text { the symptoms of meningococcal disease. A former version of the doctor's information stated that if meningococcal disease was } \\
\text { suspected, urgent medical attention and antibacterial treatment as needed were required. The revised version states that } \\
\text { meningococcal disease can be fatal or fatal without early recognition and treatment with antibiotics, and if meningococcal disease is } \\
\text { suspected or cannot be ruled out, start treatment with the appropriate antibiotic immediately. }{ }^{22}\end{array}$ \\
\hline 2017 Nov & $\begin{array}{l}\text { The review report from PMDA stated that there is a limit in risk management of meningococcal disease with emphasis on } \\
\text { vaccination only. It also stated that meningococcal disease may occur as sepsis without meningitis. }{ }^{3}\end{array}$ \\
\hline $2018 \mathrm{Mar}$ & $\begin{array}{l}\text { The marketing authorization holder released the safety information } 2^{\text {nd }} \text { report that contains specific descriptions of two cases of } \\
\text { meningococcal disease in Japan and stated that in the fatal case, a patient safety card was not presented to a physician, whereas in } \\
\text { the recovered case, the card was presented to a physician and antibiotic treatment was initiated. }{ }^{23}\end{array}$ \\
\hline $2018 \mathrm{Apr}$ & $\begin{array}{l}\text { Japanese Society of Hematology, Japanese Society of Nephrology, and Japanese Society of Neurology issued the warning that } \\
\text { meningococcal vaccination may not prevent meningococcal disease, and it is important to promptly perform examination for } \\
\text { meningococcal disease and consider antibiotic administration if high fever develops. In particular, invasive meningococcal infection } \\
\text { can occur suddenly as bacteremia without meningitis, and immediately after onset show no leukocytosis or CRP elevation, and it is } \\
\text { difficult to distinguish it from influenza or a cold. There is an acute fulminant type that can result in death from sepsis within } 24 \\
\text { hours. }^{24-26}\end{array}$ \\
\hline 2018 May & Japanese Pediatric Society also issued a warning. ${ }^{27}$ \\
\hline
\end{tabular}

Abbreviation: PMDA, Pharmaceuticals and Medical Devices Agency.

Furthermore, since the first fatal case was announced by the marketing authorization holder, five cases with a definite diagnosis of meningococcal disease have been reported.

\section{Discussion}

\section{Possible Underreporting of Deaths from Meningococcal Disease}

In post-marketing surveillance, only events containing meningococci and/or Waterhouse-Friderichsen syndrome registered in the preferred terms from Medical Dictionary for Regulatory Activities Terminology (MedDRA) are coded as meningococcal disease. ${ }^{2}$ If blood is not cultured and the patient dies without a definitive diagnosis, this case is not coded as meningococcal disease. Therefore, counting only cases with a definitive diagnosis may underestimate the risk of meningococcal disease.

There had been no reports of meningococcal disease since the start of sales until the death of the first case of meningococcal disease. Since the first report, one or two cases of meningococcal disease have been reported each year. Furthermore, the fact that 3 voluntary reports were only observed immediately after the first death report showed that the physicians involved in prescribing treatment with eculizumab were strongly affected by the risk information. It is possible that this fatal disease may not have been recognized by physicians until the first report was made.

\section{Effective Use of an All-Case Reporting System for Rare Drug Adverse Events}

In recent years, a method has been adopted in which specific serious ADRs in all users of a new drug are systematically monitored as a monitoring target. ${ }^{28}$ In Japan, there is a mandatory system for conducting postmarketing surveillance after approval of certain new drugs, and it was also applied to eculizumab. In this system, case reports are submitted at intervals of 1 week, 2 weeks, 1 month, 3, 6, 9, and 12 months after the first dose during the first year; a follow-up survey is continued until either 
death or stopping of eculizumab treatment. ${ }^{29}$ Deaths are always reported.

The present analysis of this mandatory system showed that the frequency of deaths from suspected meningococcal disease, as well as all deaths, decreased after safety information with a strong warning about meningococcal disease was issued. Death reports had increased until the $1^{\text {st }}$ quarter of 2018, in which nine deaths were reported. After that, the number of death reports started to decrease and, from the $4^{\text {th }}$ quarter of 2018 to the $2^{\text {nd }}$ quarter of 2019 , there has been only one each quarter, including a death with altered state of consciousness and DIC. Some reports only list deaths or sudden deaths as adverse events without any further information.

\section{Threat of Meningococcal Disease in Patients Receiving Eculizumab} Meningococcal versus Non-Meningococcal Infection

Not all 15 deaths suspected of meningococcal disease in the present analysis may have been meningococcal. According to the largest compilation of pharmacovigilance data on eculizumab, the overall incidence of meningococcal disease was 2.7 per 1000 person-years ( 76 per 28,518 person-years), and the mortality rate was 0.28 per 1000 person-years as of 2016 ( 8 per 28,518 person-years). ${ }^{30}$ All patients with serious, nonmeningococcal infections had severe underlying conditions, comorbidities, or treatments that could have compromised their immune systems. ${ }^{30}$ In other words, in immunocompetent patients on eculizumab, the threat of meningococcal infection is of great concern.

\section{Extreme and Rapid Clinical Course}

Invasive meningococcal disease generally has a rapid course, but it shows an extreme course in patients on eculizumab. Although initial symptoms may be minor, death can occur within a day, making it difficult to obtain a definitive diagnosis until the patient's death.

The next case shows the difficulty in making the diagnosis. A 16-year-old girl reported to an emergency department with generalized body pain, headache, and emesis $22 \mathrm{~h}$ after her second dose of eculizumab. She had no fever. Her symptoms were diagnosed as a side effect of eculizumab, and they disappeared after symptomatic treatment. Twelve hours later, she reported weakness and purpura, leading to cardiac arrest. Autopsy showed hemorrhagic cutaneous purpura, consistent with Waterhouse-Friderichsen syndrome. ${ }^{31}$ If an autopsy had not been performed, her death would not have been recognized as the result of meningococcal disease and could have been reported as sudden death with DIC.

The high mortality rate seems to be attributed to not only difficulty in diagnosis, as shown above, but also inhibition of complement activity by eculizumab. The next case was an 11year-old boy with aHUS treated with eculizumab who developed fatal meningococcemia due to Neisseria meningitidis serogroup Y 16 months after receiving two doses of quadrivalent meningococcal conjugate vaccines (MenACWY) while on oral penicillin prophylaxis. He presented to the pediatric emergency department with fever, chills, headache, and myalgia, but no rash or neck stiffness. Treatment with empirical intravenous ceftriaxone was started after blood and cerebrospinal fluid cultures were obtained. He was transferred to a pediatric intensive care unit but died within hours of PICU admission. After his death, Neisseria meningitidis serogroup $\mathrm{Y}$ was confirmed in the blood. This case highlights the difficulties in protecting patients on eculizumab treatment against meningococcal disease, even with vaccination and antibiotic prophylaxis. $^{32}$

\section{Vaccination in Japan}

In Japan, the quadrivalent meningococcal conjugate vaccine, MenACWY, was placed on the market in 2015, and patients treated with eculizumab should be vaccinated with MenACWY vaccines, but antibiotic chemoprophylaxis with oral penicillin has not been recommended. Eculizumab therapy interferes with the ability of anti-meningococcal antibodies to provide protection against invasive disease. Almost all cases of meningococcal infection occurred in patients with previous confirmed meningococcal vaccination. ${ }^{30,33,34}$ Although antimicrobial prophylaxis with penicillin for the duration of eculizumab treatment is recommended in certain countries, ${ }^{34}$ the effectiveness of this strategy for meningococcal disease prevention has not been established. Thus, the ideal management for these patients remains challenging.

\section{A Risk Mitigation Plan in Japan}

The incidence of meningococcal disease in individuals receiving eculizumab is 2.7 to 3.0 per 1000 person-years, and the mortality rate is 0.28 to 0.34 per 1000 person-years in the world. The case-fatality rate of meningococcal disease in eculizumab-exposed individuals is $10 \%$ to $11 \%$ in the world. ${ }^{2,3,30}$ In contrast, in Japan, as shown in the present analysis, the incidence is lower, at 1.7 per 1000 personyears, but the mortality rate is higher, at 0.56 per 1000 person-years. The case-fatality rate is $33 \%$, three times higher than that in the world. Given the very low incidence of 
meningococcal disease and the carriage rates of meningococci in the general population in Japan, the above results are surprising. The risk of meningococcal disease due to eculizumab in Japan is similar to that in the world.

Higher mortality and lower incidence in Japan may be ascribed to less alertness because of the overall low incidence of meningococcal disease in the population in Japan (1/10 to $1 / 100$ of the incidence in the world) and to the overlooking and underreporting of the disease. The lower the accuracy of diagnosis of meningococcal infection is, the lower the incidence is. In cases of death, the accuracy of diagnosis is probably higher than in cases of recovery, which may lead to a higher calculated case-fatality rate. Increasing diagnosis rates for meningococcal infections may change the incidence and mortality rates of patients on eculizumab in Japan.

The risk management system for eculizumab-related meningococcal disease should assume that physicians with little knowledge of meningococcal disease and who do not know about eculizumab will examine patients in the emergency setting. A patient safety card is a powerful tool for risk communication in this setting. It teaches patients the early symptoms and educates them about the need to take appropriate action. The physicians presented with the card can take specific actions without any prior knowledge. The key to using the card properly is patient education.

A series of risk communications seemed to be effective, because the number of all deaths has been decreasing since the safety information was repeatedly issued, and there have been no reports of deaths due to meningococcal infections since 2016. At present, data accumulation in Japan may be insufficient, but risk assessment should continue to be performed properly based on the results of post-marketing surveillance.

\section{Conclusion}

Originally, the incidence of meningococcal infection was extremely low in Japan, and no meningococcal disease had been reported for six years after the launch of eculizumab. However, by analyzing the death reports in the JADER database, there were 17 deaths with symptoms of suspected meningococcal infection between 2010 and 2018, which suggests that some cases of true meningococcal disease had simply been undiagnosed. After the marketing authorization holder and several academic associations provided critical information on the risk management of eculizumab-related meningococcal disease, the number of death reports has decreased. A decrease in deaths may indicate that risk communication has been successful.

\section{Abbreviations}

PNH, paroxysmal nocturnal hemoglobinuria; DIC, disseminated intravascular coagulation; aHUS, atypical hemolytic uremic syndrome; gMG, generalized myasthenia gravis; NMOSDs, neuromyelitis optica spectrum disorders; JADER, Japanese Adverse Drug Event Report; ADRs, adverse drug reactions; PMDA, Pharmaceuticals and Medical Devices Agency; MedDRA, Medical Dictionary for Regulatory Activities Terminology; NESID, National Epidemiological Surveillance of Infectious Disease.

\section{Data Sharing Statement}

The datasets from the JADER database, National Epidemiological Surveillance of Infectious Disease, and the portal site of official statistics of Japan are freely available.

\section{Acknowledgments}

The author wishes to thank all of the contributors to the JADER database.

\section{Disclosure}

The author reports no conflicts of interest in this work.

\section{References}

1. Lewis LA, Ram S. Meningococcal disease, and the complement system. Virulence. 2014;5(1):98-126. doi:10.4161/viru.26515

2. Soliris Review Report (October 16, 2019). Available from http://www. pmda.go.jp/drugs/2019/P20191205001/870056000_ 22200AMX00316_A100_1.pdf. Accessed January 17, 2020.

3. Soliris Review Report (November 24, 2017). Available from http:// www.pmda.go.jp/drugs/2018/P20180110001/870056000_ 22200AMX00316_A100_2.pdf. Accessed January 17, 2020.

4. Thompson MJ, Ninis $\bar{N}$, Perera R, et al. Clinical recognition of meningococcal disease in children and adolescents. Lancet. 2006;367 (9508):397-403. doi:10.1016/S0140-6736(06)67932-4

5. European Centre for Disease Prevention and Control. Factsheet about meningococcal disease. Available from https://www.ecdc.europa.eu/ en/meningococcal-disease/factsheet. Accessed January 3, 2020.

6. The Department of Health. Meningococcal Disease (Invasive). Available from https://www1.health.gov.au/internet/main/publishing. nsf/Content/ohp-meningococcal-W.htm. Accessed January 12, 2020.

7. Public health surveillance. Information for New Zealand Public Health Action. Invasive meningococcal disease report. Available from https:// surv.esr.cri.nz/PDF_surveillance/MeningococcalDisease/2019/ MeningococcalDisease_wk2-32019.pdf

8. Olea A, Matute I, González C, et al. Case-control study of risk factors for meningococcal disease in Chile. Emerg Infect Dis. 2017;23 (7):1070-1078. doi:10.3201/eid2307.160129 
9. Gentile A, Bakir J, Agosti MR, et al. Meningococcal disease in children in Argentina: A 3-year active sentinel hospital surveillance study. Pediatr Infect Dis J. 2017;36:296-300. doi:10.1097/INF.0000 000000001429

10. Li YA, Tsang R, Desai S, Deehan H. Enhanced surveillance of invasive meningococcal disease in Canada, 2006-2011. Can Comm Dis Rep. 2014;40(9):160-169. doi:10.14745/ccdr.v40i09a01

11. Centers for Disease Control and Prevention. Meningococcal disease. Available from https://www.cdc.gov/vaccines/pubs/surv-manual /chpt08-mening.pdf. Accessed July 24, 2020.

12. Fernandez K, Lingani C, Aderinola OM, et al. Meningococcal meningitis outbreaks in the African meningitis belt after meningococcal serogroup A conjugate vaccine introduction, 2011-2017. J Infect Dis. 2019;220(Supplement_4):225-232. doi:10.1093/infdis/jiz355

13. Fukusumi M, Kamiya H, Takahashi H, et al. National surveillance for meningococcal disease in Japan, 1999-2014. Vaccine. 2016;34 (34):4068-4071. doi:10.1016/j.vaccine.2016.06.018

14. National Institute of Infectious Diseases. Invasive meningococcal infection April 2013-October 2017. IASR. 2018;39:1-2.

15. Caugant DA, Maiden MC. Meningococcal carriage and diseasepopulation biology and evolution. Vaccine. 2009;27(Suppl):B64-70. doi:10.1016/j.vaccine.2009.04.061

16. Tanaka H, Kuroki T, Watanabe Y, et al. Isolation of Neisseria meningitidis from healthy persons in Japan. Kansenshogaku Zasshi. 2005;79(8):527-533. doi:10.11150/kansenshogakuzasshi1970.79.527

17. Mori E, Kaneko M, Narukawa M. The Current Status of All-Case Surveillance Study in Japan and Factors Influencing the Judgment of Its Necessity. Jpn J Clin Pharmacol Ther. 2015;46(4):185-189. doi:10.3999/jscpt.46.185

18. The Portal Site of Official Statistics of Japan, e-Stat. Population Estimates. Available from https://www.e-stat.go.jp/stat-search?page= $1 \&$ layout $=$ normal $\&$ toukei $=00200524 \&$ survey $=\% \mathrm{E} 4 \% \mathrm{BA} \% \mathrm{BA} \%$ E5\%8F\%A3. Accessed January 21, 2020.

19. Pharmaceuticals and Medical Devices Agency. ADR information for eculizumab from the first quarter of 2010 to the second quarter of 2019. Available from: https://www.pmda.go.jp/safety/info-services/ drugs/adr-info/suspected-adr/0003.html. Accessed January 3, 2020

20. Alexion Pharma Co., Ltd. Safety information for Soliris ${ }^{\circledR}$ Intravenous Infusion $300 \mathrm{mg}$ (Created in October 2016). Available from http://www. soliris.jp/common/pdf/SOL_safty.pdf. Accessed January 18, 2020.

21. Alexion Pharma Co., Ltd. SOLIRIS ${ }^{\circledR}$ Intravenous Infusion $300 \mathrm{Mg}$ [Package Insert]. 8th edition. Japanese; 2017.

22. Alexion Pharma Co., Ltd. Soliris ${ }^{\circledR}$ Patient Safety Card SOL-Card -1709 Japanese; 2015.

23. Alexion Pharma Co., Ltd. Safety information for Soliris ${ }^{\circledR}$ Intravenous Infusion $300 \mathrm{mg}$ 2nd report (published in Mar 2018) Available from http://www.soliris.jp/common/pdf/sol_safty2.pdf. Accessed February 2, 2020
24. Japanese Society of Hematology. Notes and countermeasures when using Soliris. Available from http:/www.jshem.or.jp/uploads/files/ medical/ 20180424\%20Soliris.pdf. Accessed February 2, 2020.

25. Japanese Society of Nephrology. Notes and countermeasures when using Soliris. Available from https:/www.jsn.or.jp/topics/notice/ 3430.php. Accessed February 2, 2020.

26. Japanese Society of Neurology. Notes on using Soliris ${ }^{\circledR}$ approved for systemic myasthenia gravis. Available from https://www.neurologyjp.org/news/news 20180109 01.html. Accessed February 2, 2020.

27. Japanese Society of Pediatrics. Attention about meningococcal disease caused by administration of Soliris (eculizumab) IV $300 \mathrm{mg}$. Available from https://www.jpeds.or.jp/uploads/files/201805Soliris. pdf. Accessed February 2, 2020.

28. Kubota K. Regulatory Aspects of Pharmacovigilance. In: An Introduction to Pharmacovigilance. Second Edition. Tokyo: Jiho; 2018:89-111.

29. Ninomiya $H$, Obara $N$, Chiba $S$. et al. Interim analysis of post-marketing surveillance of eculizumab for paroxysmal nocturnal hemoglobinuria in Japan. Int $J$ Hematol. 2016;104(5):548-558. doi:10.1007/s12185-016-2065-4

30. Socié G, Caby-Tosi MP, Marantz JL, et al. Eculizumab in paroxysmal nocturnal haemoglobinuria and atypical haemolytic uraemic syndrome: 10-year pharmacovigilance analysis. Br J Haematol. 2019; 185(2):297. doi:10.1111/bjh.15790

31. Nolfi-Donegan D, Konar M, Vianzon V, et al. Fatal Nongroupable Neisseria meningitidis Disease in Vaccinated Patient Receiving Eculizumab. Emerg Infect Dis. 2018;24(8):1561-1564. doi:10.3201/ eid2408.180228

32. Polat M, Yüksel S, Şahin NÜ. Fatal meningococcemia due to Neisseria Meningitidis serogroup $\mathrm{Y}$ in a vaccinated child receiving eculizumab. Hum Vaccin Immunother. 2018;14:2802.

33. Dretler AW, Rouphael NG, Stephens DS. Progress toward the global control of Neisseria meningitidis: 21st century vaccines, current guidelines, and challenges for future vaccine development. Hum Vaccin Immunother. 2018;14(5):1146-1160. doi:10.1080/21645515. 2018.1451810

34. McNamara LA, Topaz N, Wang X Hariri S, Fox L, MacNeil JR. High risk for invasive meningococcal disease among patients receiving eculizumab (Soliris) despite receipt of meningococcal vaccine. Morb Mortal Wkly Rep. 2017;66:734-737.
Drug, Healthcare and Patient Safety

\section{Publish your work in this journal}

Drug, Healthcare and Patient Safety is an international, peer-reviewed open-access journal exploring patient safety issues in the healthcare continuum from diagnostic and screening interventions through to treatment, drug therapy and surgery. The journal is characterized by the rapid reporting of reviews, original research, clinical, epidemiological and post-marketing surveillance studies, risk management, health literacy and educational programs across all areas of healthcare delivery. The manuscript management system is completely online and includes a very quick and fair peer-review system. Visit http://www.dovepress.com/testimonials.php to read real quotes from published authors. 